\title{
Decreased nitric oxide in the exhaled air of patients with systemic sclerosis with pulmonary hypertension
}

Sergei A Kharitonov, Jeremy B Cailes, Carol M Black, Roland M du Bois, Peter J Barnes

\begin{abstract}
Background - Systemic sclerosis (SSc) may be complicated by pulmonary hypertension (PHT), which can occur both in the setting of fibrosing alveolitis or as lone pulmonary vascular disease. Nitric oxide (NO) is a powerful vasodilator and is produced by various cells in the respiratory tract including pulmonary vascular endothelial cells and can be measured in expired air. A study was undertaken to test the hypothesis that exhaled NO levels would be decreased in patients with SSc with PHT and to assess the utility of this measurement in discriminating between patients with and without PHT, regardless of concurrent fibrosing alveolitis.
\end{abstract}

Methods - Exhaled NO was measured with a chemiluminescence analyser in 23 patients with SSc (six with PHT, 17 subjects without) and in 67 normal individuals. Doppler echocardiography was used to assess pulmonary artery pressure in subjects with SSc, and lung function tests were performed at the same visit as NO measurements. Thin section CT scans were analysed for the presence of abnormality consistent with fibrosing alveolitis.

Results - Patients with SSc with PHT had a greater reduction in arterial oxygen tension $\left(\mathrm{PaO}_{2}\right)$ and carbon monoxide gas transfer (TLCO) than patients with SSc without PHT. Exhaled NO was significantly higher in patients with SSc without PHT than in normal individuals, and was significantly decreased in patients with SSc with PHT (mean (SD) 20 (6) ppb) compared with 149 (19) ppb in those with SSc without PHT (mean difference 129 (95\% CI 112 to 146) ppb) and 80 (7) ppb in normal individuals (mean difference 60 (95\% CI 54 to 66) ppb).

Conclusions - Exhaled NO is decreased in patients with SSc with PHT compared with both normal individuals and patients with SSc without PHT.

(Thorax 1997;52:1051-1055)

Keywords: systemic sclerosis, nitric oxide, pulmonary hypertension, fibrosing alveolitis.

Systemic sclerosis (SSc) is a connective tissue disease and is often complicated by pulmonary hypertension $(\mathrm{PHT})^{1}$ which may occur in the absence of parenchymal lung disease or in con- junction with fibrosing alveolitis. In SSc complicated by PHT the pulmonary vasculature responsiveness to vasodilator medications is often altered. ${ }^{2}$ When PHT complicates SSc the prognosis for survival is poor, and pulmonary disease complicated by PHT is the most common cause of death in these patients. ${ }^{3}$

The mechanism underlying the development of PHT in SSc is unknown. In other interstitial lung diseases PHT normally occurs as a late complication of severe fibrosis or may occur in the presence or absence of parenchymal lung disease or in conjunction with fibrosing alveolitis. In SSc, however, PHT may occur with minor or no parenchymal fibrosis, suggesting that different mechanisms may be involved in the development of pulmonary vascular disease. Systemic sclerosis is characterised by widespread vascular disease which can be manifested in many organs. Endothelial morphological $^{4-6}$ and functional ${ }^{7}$ changes have been found in patients with early SSc, suggesting that such abnormalities may be important in the genesis of vascular disease in this condition. The importance of endothelium and endothelium derived factors in controlling the pulmonary vasculature has been increasingly recognised. ${ }^{89}$

Once PHT has developed it is easily diagnosed by Doppler echocardiography, but to identify patients at risk of developing PHT is more difficult. A reduction in carbon monoxide transfer factor (TLCO), particularly to less than $50 \%$ of the predicted value, is recognised as a risk factor for PHT. The specificity of this test is low, however, and there remains the need for a test to identify reliably those patients with SSc who will develop PHT.

$\mathrm{NO}$ is produced constitutively by the enzyme nitric oxide synthase (NOS) in endothelial cells and is measurable in exhaled air in normal human subjects. ${ }^{10-12}$ It diffuses into adjacent vascular smooth muscle cells and binds to soluble guanylate cyclase, stimulating the production of cyclic guanosine $3^{\prime} 5^{\prime}$-monophosphate (cGMP) which results in muscle relaxation. ${ }^{13}$ Reduced expression of endothelial nitric oxide synthase (NOS) has been identified in the lung of patients with pulmonary hypertension. ${ }^{14}$ It is possible that decreased expression of NOS may contribute to pulmonary vasoconstriction and to the excessive growth of the tunica media observed in this disease.

Deficiency of NO could contribute to the development of PHT in SSc, and may be a non-invasive marker of disease risk. We hypo- 
thesised that subjects with $\mathrm{SSc}$ and PHT may have decreased levels of exhaled NO. Exhaled NO was therefore measured in these subjects and compared with levels in those with SSc without PHT and with normal individuals with no evidence of lung disease.

\section{Methods}

PATIENTS

Twenty three patients with a diagnosis of systemic sclerosis based on the preliminary criteria of the American Rheumatism Association ${ }^{15}$ were studied. Patients were not considered for entry if there was evidence of any of the following conditions: (1) rheumatological overlap syndromes, (2) systemic hypertension, (3) airways disease, (4) respiratory tract infection, (5) cardiac disease not related to SSc, or (6) if they were current smokers. Medication history was obtained from each patient with specific questions regarding the use of glucocorticosteroids and vasodilator medications. Patients with SSc and PHT were also compared with a group of 67 normal non-smoking individuals (40 men) of mean (SD) age 36 (7) years with no evidence of lung according to respiratory questionnaires and normal lung function (forced expiratory volume in one second $\left(\mathrm{FEV}_{1}\right) 98$ (2.4)\% predicted). Although normal individuals were not age or sex-matched, no relationship between sex, age, and exhaled NO has been reported, at least in adults. ${ }^{1617}$

ASSESSMENT OF PULMONARY HYPERTENSION A non-invasive method of assessment of pulmonary pressure was considered to be more appropriate in this study. Pulmonary artery systolic pressure was estimated by Doppler echocardiography. M-mode and cross sectional echocardiography (Hewlett Packard (Andover, Massachusetts, USA) was performed with the patient in the left lateral position. Non-imaging continuous wave Doppler signals were recorded with a Doptek (Southampton, UK) 2.0 MHZ transducer. Regurgitant flow was identified in continuous wave mode at the apex. The peak instantaneous systolic pressure drop from right ventricle to atrium was calculated from the peak signal velocity of the tricuspid regurgitant signal by the simplified Bernoulli equation. The final estimation of pulmonary artery systolic pressure was obtained by adding the jugular venous pressure to the estimated pulmonary artery systolic pressure. PHT was diagnosed if pulmonary artery systolic pressure was estimated to be over $30 \mathrm{mmHg}$. Exclusion of PHT required both the demonstration of a structurally normal right ventricle and a time interval between pulmonary valve closure and the start of tricuspid flow of less than $50 \mathrm{~ms} .^{18}$

ASSESSMENT OF FIBROSING ALVEOLITIS

All patients underwent thin section $(3 \mathrm{~mm})$ computed tomographic (CT) scanning (Imatron Inc, San Francisco, USA) of the lungs prior to measurement of exhaled NO levels. Scans were analysed by an experienced thoracic radiologist and an assessment made of the presence or absence of a pattern consistent with fibrosing alveolitis.

\section{PULMONARY FUNCTION TESTING}

Pulmonary function tests were performed at the same visit as measurement of exhaled NO. Forced expiratory flow volume curves were obtained using a dry rolling seal spirometer (PK Morgan Ltd, Gillingham, UK). TLCO was measured by a rebreathing manoeuvre using modified $^{19}$ transfer factor equipment (PK Morgan Ltd) and results amended to a 10 second single breath result. Arterialised capillary blood gases were taken ${ }^{20}$ and analysed using a Corning 178 blood gas analyser (Ciba Corning, Halstead, Essex, UK). Indices are expressed as percentage of predicted normal. ${ }^{2122}$

MEASUREMENT OF EXHALED NITRIC OXIDE

Peak exhaled NO was measured using a chemiluminescence analyser (Dasibi Environmental Corporation, Glendale, California, USA) specifically adapted for on-line recording of $\mathrm{NO}$ levels using a technique previously described. ${ }^{23}$ The sensitivity of the analyser ranged from $2 \mathrm{ppb}$ to $4000 \mathrm{ppb}$ by volume. Subjects performed a slow exhalation with flow rate of $500 \mathrm{ml} / \mathrm{min}$ from vital capacity over $30-45 \mathrm{sec}-$ onds into wide bore Teflon tubing with NO being sampled continuously at a flow rate $250 \mathrm{ml} / \mathrm{min}$. Three technically adequate recordings were made and an average of the peak values taken as the exhaled NO level. The coefficient of variation between the three exhalations used for subsequent analysis was $7 \%$.

\section{STATISTICAL ANALYSIS}

ANOVA test was used for comparisons between two groups. Linear regression analysis was used to assess the relationship between exhaled $\mathrm{NO}$ and the arterial oxygen tension $\left(\mathrm{PaO}_{2}\right)$ and multiple linear regression analysis was used to assess whether the presence of PHT was independently related to exhaled NO (square root transformation) using SPSS for Windows software. ${ }^{24}$

\section{Results}

Patients with SSc were characterised on the basis of Doppler estimates of pulmonary artery systolic pressure (tables 1 and 2). The percentage of patients with fibrosing alveolitis in each group was almost identical, and forced vital capacity (FVC) measures suggested a similar physiological extent of fibrotic disease in the

Table 1 Age and sex characteristics of patient groups

\begin{tabular}{llll}
\hline & $\begin{array}{l}\text { Controls } \\
(n=67)\end{array}$ & $\begin{array}{l}S S c \\
(n=17)\end{array}$ & $\begin{array}{l}S S c P H T \\
(n=6)\end{array}$ \\
\hline Mean (SD) age (years) & $36(7)$ & $50(11)$ & $61(10)$ \\
Sex (F:M) & $27: 40$ & $10: 7$ & $5: 1$ \\
\hline
\end{tabular}

Control $=$ normal subjects; $\mathrm{SSc}=$ systemic sclerosis with no pul monary hypertension (PHT); SSc PHT = systemic sclerosis with PHT. 
Table 2 Mean (SD) lung function and arterial blood oxygen tension in patients with systemic sclerosis

\begin{tabular}{|c|c|c|c|}
\hline & $\begin{array}{l}S S c \\
(n=17)\end{array}$ & $\begin{array}{l}S S c P H T \\
(n=6)\end{array}$ & $p$ value \\
\hline FVC (\% predicted) & $95 \quad(23)$ & (26) & 0.29 \\
\hline TLCO (\% predicted) & 63 (23) & 42 (14) & 0.05 \\
\hline $\mathrm{PaO}_{2}(\mathrm{kPa})$ & $11.5(1.3)$ & $8.8(1.5)$ & 0.002 \\
\hline
\end{tabular}

$\mathrm{SSc}=$ systemic sclerosis with no pulmonary hypertension (PHT); SSc PHT = systemic sclerosis with PHT; FVC = forced vital capacity; $\mathrm{TLCO}=$ carbon monoxide transfer factor; $\mathrm{PaO}_{2}=$ arterial oxygen tension.

Table 3 Disease and treatment variables for subjects with systemic sclerosis

\begin{tabular}{lcl}
\hline & $\begin{array}{ll}S S c \\
(n=17)\end{array}$ & $\begin{array}{l}S S c P H T \\
(n=6)\end{array}$ \\
\hline Ever smokers & 7 & 2 \\
CT fibrosis & 11 & 4 \\
Treatment with glucocorticoids & 8 & 3 \\
Treatment with vasodilators & 6 & 3 \\
\hline
\end{tabular}

$\mathrm{SSc}=$ systemic sclerosis with no pulmonary hypertension (PHT); SSc PHT = systemic sclerosis with PHT; CT fibrosis = CT scan pattern consistent with fibrosing alveolitis.

two groups. Treatment that could potentially affect exhaled NO (glucocorticoids or vasodilator medications) was also similar in the two disease groups (table 3).

Exhaled NO was significantly lower in the patients with SSc and PHT (mean (SD) 20 (6) $\mathrm{ppb}$ ) than in those with SSc without PHT (149 (19) ppb, p<0.001; fig 1). Exhaled NO was significantly higher in normal subjects ( 80 (7) $\mathrm{ppb}$ ) than in patients with SSc and PHT $(p<0.002)$ and significantly lower than in those with SSc without PHT (149 (19) ppb, $\mathrm{p}<0.004)$, raising the possibility that either endothelial cells or inflammatory cells in the lower respiratory tract in subjects with SSc may be producing increased amounts of NO.

There was no relationship between $\mathrm{NO}$ and $\mathrm{PaO}_{2}$ in patients with SSc with PHT $(r=0.04$, $\mathrm{p}=0.94$ ) but there was negative correlation between these two parameters in patients with SSc without PHT ( $r=-0.49, \mathrm{p}<0.05$; fig 2$)$. There was no relationship between exhaled NO and TLCO in patients with SSc either with $(r=0.2, \mathrm{p}=0.71)$ or without $(r=0.1, \mathrm{p}=0.76)$ PHT. No correlation was found between exhaled NO and pulmonary artery pressure $(r=$ $-0.3, \mathrm{p}=0.12)$.

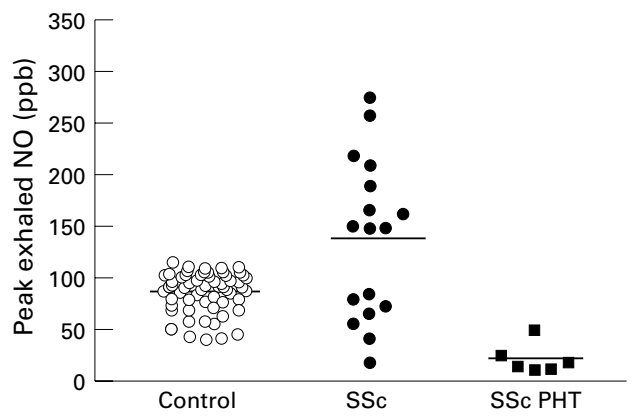

Figure 1 Exhaled NO in normal individuals and subjects with systemic sclerosis (SSc) with and without evidence of pulmonary hypertension (PHT) compared with controls with no evidence of lung disease.

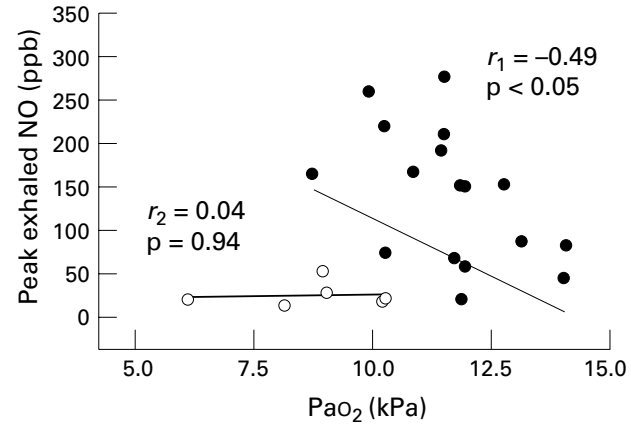

Figure 2 Correlation between exhaled $\mathrm{NO}$ and arterial oxygen tension $\left(\mathrm{PaO}_{2}\right)$ in patients with systemic sclerosis with (○) or without (O) pulmonary hypertension.

\section{Discussion}

Release of NO by vascular endothelial cells is involved in regulation of vascular resistance. We have shown that in systemic sclerosis complicated by pulmonary hypertension there was a significant reduction in exhaled NO which was independent of age, sex, presence and physiological extent of fibrosing alveolitis.

Many cells residing within the respiratory tract have the potential to release $\mathrm{NO}$ including endothelial cells, neutrophils, ${ }^{25}$ epithelial cells, ${ }^{26}$ and vascular smooth muscle cells. ${ }^{27}$ However, the precise source of $\mathrm{NO}$ in exhaled air is unknown. NO is produced in high concentrations in the upper respiratory tract and there has been concern that this may contaminate exhaled air. However, direct measurement of NO via a bronchoscope has shown that levels measured at the mouth reflect levels in the lower respiratory tract and that nasal contamination is not a problem providing $\mathrm{NO}$ measurements are made during exhalation against a resistance causing soft palate closure. ${ }^{28} 29$

In research and clinical trials the true pulmonary artery pressure and right ventricular status relevant to prognosis and other tests of function are considered to be shown by cardiac catheterisation. However, a poorly prepared patient may find catheterisation frightening and painful. Right heart pressures are normally so low that anxiety and alterations in breathing pattern and oxygenation may change them appreciably. A further difficulty is that catheterisation and non-invasive tests usually examine different aspects of the right ventricle (pressures, wall thickness, or cavity size) related to the general problem of cor pulmonale. Noninvasive tests are usually performed at rest and have, in general, been assessed for their ability to predict mean resting pulmonary artery pressure. Although the estimation of pulmonary hypertension using Doppler echocardiography is less accurate than pulmonary catheterisation, the non-invasive method of assessment of pulmonary pressure has been chosen as more appropriate in this study.

We found exhaled NO to be significantly higher in subjects with SSc without PHT than in normal control subjects. This could be attributed to increased numbers of inflammatory cells (macrophages and neutrophils) which are 
frequently found in bronchoalveolar lavage fluid of patients with SSc and fibrosing alveolitis $^{30}$ and could release increased amounts of NO.

Recently, little expression of inducible NOS (iNOS) and nitrotyrosine has been shown in the airway epithelium in normal lungs. ${ }^{31}$ In contrast, lungs of patients with early to intermediate pulmonary fibrosis showed abundant expression for both constitutive and inducible forms of NOS and peroxynitrite in the alveolar epithelium and inflammatory cells. ${ }^{31}$ Sustained high levels of NO, produced mainly by $\mathrm{iNOS}^{12}$ and mediated by nitrogen dioxide and/or peroxynitrite, may have severe pathological implications in pulmonary fibrosis. Oxidation of NO or decomposition of peroxynitrite produces the reactive free radicals which have been shown in the rat to cause pulmonary parenchymal and vascular alterations similar to those seen in pulmonary fibrosis. ${ }^{32-34}$

Although the mechanism underlying the development of PHT in systemic sclerosis is complex and unknown, there is some evidence that NO may play a part in the development of PHT or simply reflect the loss of a vascular bed. Thus, there was almost no iNOS expression in alveolar epithelium and inflammatory cells in patients with end-stage pulmonary fibrosis and pulmonary hypertension. ${ }^{31}$ Indeed, exhaled NO levels were significantly decreased in patients with SSc and PHT compared with patients without PHT.

The presence of raised pulmonary artery pressure in the pulmonary hypertensive group also implies a comparatively greater degree of structural damage to the pulmonary arterial tree with a smaller number of endothelial cells available to release NO into expired air. Endothelial dysfunction in the pulmonary hypertensive patients may therefore be an additional cause of the low exhaled NO levels observed in this group. Indeed, TLCO was significantly reduced in the group with PHT, suggesting a reduction in effective capillary blood volume.

The reduction in NO release could be simply a consequence of the pulmonary hypertension. However, considering the role of NO in pulmonary circulatory regulation and the fact that $\mathrm{NO}$ is a powerful endogenous and exogenous vasodilator, the existence of a complex pathogenesis of pulmonary hypertension development and the role of $\mathrm{NO}$ as a causative agent cannot be excluded. Moreover, the reduction in NO release might be a useful marker of the presence of pulmonary hypertension rather than a marker of a propensity for pulmonary hypertension.

The effect of hypoxia on NO production is controversial. Although the negative correlation between exhaled $\mathrm{NO}$ and $\mathrm{PaO}_{2}$ in patients with PHT may simply reflect the presence of worse systemic sclerosis, the loss of endothelially mediated vasodilatation in conditions associated with chronic hypoxia ${ }^{3536}$ has been demonstrated, suggesting deficient production of NO. Alternatively, an increase in pulmonary artery pressure has been shown when NO synthesis is inhibited, ${ }^{3738}$ suggesting a possible protective vasodilatory role for NO in patients with pulmonary hypertension and hypoxia. ${ }^{39}$ It is possible that patients with SSc without PHT have pulmonary endothelial cells that are able to respond to mild hypoxia by increasing NO production, thus explaining the increased levels in exhaled breath. We speculate that patients with PHT have significant endothelial dysfunction and are unable to increase NO production.

There is substantial evidence that the endothelium is damaged early in the course of SSc. Increased levels of von Willebrand's factor antigen, considered indicative of endothelial injury, are found early in the course of the illness. ${ }^{4041}$ Studies examining skin in patients with SSc suggest that the initial vascular insult is focused on the endothelial cell ${ }^{4-6}$ and that vascular damage occurs before other pathological changes such as fibrosis. Data regarding the pulmonary endothelial cell in SSc are limited. However, increased albumin levels have been found in bronchoalveolar lavage fluid in patients without fibrosing alveolitis, suggesting that abnormal endothelial permeability occurs early in the disease. ${ }^{42}$ The mechanism of endothelial damage in SSc is unclear, but unidentified circulating substances present in serum from patients with SSc have the potential to cause morphological changes to endothelial cells in culture, and could potentially be involved in mediating endothelial damage. ${ }^{43-45}$

There are several ways in which diminished endothelial cell production of NO could be involved in the development of PHT in patients with SSc. Diminished production of this endogenous vasodilator could lead to the unopposed action of vasoconstrictor substances such as endothelin-1 (ET-1), increasing pulmonary vascular resistance. Additionally, impairment of NO release could augment endothelial expression of ET- $1 .{ }^{46} \mathrm{NO}$ deficiency may not only cause vasoconstriction but may lead to obstructive and proliferative changes in pulmonary arteries.

$\mathrm{NO}$ is known to be an inhibitor of platelet adhesion to vascular endothelium. ${ }^{47-49}$ Impairment of $\mathrm{NO}$ release could therefore encourage in situ thrombosis, worsening vascular narrowing caused by vasoconstriction, ${ }^{50}$ and increase monocyte migration into the vascular wall, ${ }^{5152}$ encouraging fibrointimal proliferation. ${ }^{5354}$

Pulmonary hypertension may be difficult to diagnose, especially at an early stage. In SSc a decrease in TLCO is recognised as a risk factor for development of PHT. ${ }^{2}$ Depression of TLCO is, however, relatively common in SSc and reflects the loss of effective capillary blood flow. ${ }^{55}$ A test that identified patients with SSc at significantly increased risk for the development of PHT would be valuable as it is likely that any intervention that could alter the natural history of this condition would need to be initiated before there were marked structural changes in the pulmonary vessels. We have found significantly decreased levels of exhaled NO in subjects with SSc and PHT compared with both those with SSc without PHT and normal individuals. Though the cellular origin of exhaled NO is not known, these results are consistent with the concept that in patients with 
SSc and PHT there is diminished endothelial production of NO. Further investigation of $\mathrm{NO}$ production by the pulmonary vascular endothelium in systemic sclerosis is likely to help to define the mechanism of development of pulmonary hypertension in this condition.

This study was funded by the British Lung Foundation (UK) and the Raynaud's and Scleroderma Association (UK).

1 Ungerer RG, Tashkin DP, Furst D, Clements PJ, Gong H $\mathrm{Jr}$, Bein $\mathrm{M}$, et al. Prevalence and clinical correlates of pulmonary arteriat hypertension in progressive systemic sclerosis. Am f Med 1983;75:65-74.

2 Stupi AM, Steen VD, Owens GR, Barnes EL, Rodnan GP, Medsger TA Jr. Pulmonary hypertension in the CREST syndrome variant of systemic sclerosis. Arthritis Rheum 1986;29:515-24.

3 Lee P, Langevitz P, Alderdice CA, Aubrey M, Baer PA, Baron M, et al. Mortality in systemic sclerosis (scleroderma). Q F Med 1992;82:139-148.

4 Claman HN, Giorno RC, Seibold JR. Endothelial and "uroblastic activation in scleroderma. The myth of the

5 Freemont AJ, Hoyland J, Fielding P, Hodson N, Jayson NU. Studies of the microvascular endothelium in uninvolved skin of patients with systemic sclerosis: direct evidence for a generalised microangiopathy. BrF Dermatol 1992;126:561-8.

6 Prescott RJ, Freemont AJ, Jones CJ, Hoyland J, Fielding P. Sequential dermal microvascular and perivascular changes in the development of scleroderma. F Pathol 1992;166: 255-63.

7 Matucci-Cerinic M, Pietrini U, Marabini S. Local venomotor response to intravenous infusion of substance $\mathrm{P}$ and glyceryl trinitrate in systemic sclerosis. Clin Exp Rheumatol 1990;8:561-5.

8 McCormack D. Endothelium-derived relaxing factors and the human pulmonary circulation. Lung 1990;168(Suppl): $35-42$.

9 Dinh-Xuan AT. Endothelial modulation of pulmonary vascular tone. Eur Respir f 1992;5:757-62.

10 Gustafsson LE, Leone AM, Persson MG, Wiklund NP, Moncada S. Endogenous nitric oxide is present in the exhaled air of rabbits, guinea pigs and humans. Biochem Biophys Res Commun 1991;181:852-7.

11 Borland CD, Cox Y, Higenbottam T. Measurement of exhaled nitric oxide in man. Thorax 1993;48:1160-2.

12 Barnes PJ, Beivisi MG. Nitric oxide and lung disease. Thorax 1993;48:1034-43.

13 Barnes PJ, Kharitonov SA. Exhaled nitric oxide: a new lung function test. Thorax 1996;51:233-7.

14 Giad A, Saleh D. Reduced expression of endothelial nitric oxide synthase in the lungs of patients with pulmonary hypertension. N Engl f Med 1995;333:214-21.

15 Subcommittee for Scleroderma Criteria of the American Rheumatism Association Diagnostic Therapeutic Criteria Committee. Preliminary criteria for the classification of Committee. Preliminary criteria for the classification of
systemic sclerosis (scleroderma). Arthritis Rheum 1980;23: 581-90.

16 Kharitonov SA, Logan-Sinclair RB, Busset CM, Shinebourne EA. Peak expiratory nitric oxide differences in men and women: relation to the menstrual cycle. Br Heart f 1994;72:243-5.

17 Kharitonov SA, Lalloo UG, Barnes PJ. Reference values of exhaled and nasal nitric oxide for women and men 20 to 85 years of age. Am $\mathcal{F}$ Respir Crit Care Med 1977;155: A 825 .

18 Brecker SJ, Xiao HB, Stojnic BB, Mbaissouroum M, Gibson DG. Assessment of the peak tricuspid regurgitant velocity from the dynamics of retrograde flow. Int 7 Cardiol 1992; 34:267-71.

19 Denison DM, Cramer DS, Hanson PJ. Lung function testing and AIDS. Respir Med 1989;83:133-8.

20 Spiro SG, Dowdeswell IR. Arterialised ear lobe blood samples for blood gas tensions. Br $\mathcal{F}$ Dis Chest 1976;70: 263-8.

21 Cotes JE, Chimi DJ, Quanjer PH, Roca J, Yemault JC. Standardisation of the measurement of transfer factor
(diffusing capacity). Report Working Party Stand(diffusing capacity). Report Working Party Standardisation of Lung Function Tests, European Community for Steel and Coal. Official Stat

22 Quanier PH, Tanimeling GJ, Cotes JE, Pedersen OF, Peslin $\mathrm{R}$, Yemault JC. Lung volumes and forced ventilators flows. Report Working Party Standardisation of Lung Function Tests, European Community for Steel and Coal, Official Statement of the ERS. Eur Respir f Suppl 1993;16:5-40.

23 Kharitonov SA, Yates D, Robbins RA, Logan-Sinclair R, Shinebourne EA, Barnes PJ. Increased nitric oxide in exhaled air of asthmatic patients. Lancet 1994;343:133-5.

24 Norusis MJ. SPSS for windows. Base system users guide, release 6.0. Chicago: SPSS Inc, 1993:1-828.

25 Moncada S, Higgs A. The L-arginine-nitric oxide pathway. $N$ Engl f Med 1993;329:2002-12.

26 Robbins RA, Barnes PJ, Springall DR, Warren JB, Kwon OJ, Buttery LDK, et al. Expression of inducible nitric
oxide in human lung epithelial cells. Biochem Biophys Res Commun 1994;203:209-18.
27 Bernhardt J, Tschudi M, Dohi Y, Gut I, Urwyler B, Buhler $\mathrm{FR}$, et al. Release of nitric oxide from human vascular smooth muscle cells. Biochem Biophys Res Commun 1991 180:907-12.

28 Kharitonov SA, Chung FK, Evans DJ, O’Connor BJ, Barnes PJ. The elevated level of exhaled nitric oxide in asthmatic patients is mainly derived from the lower respiratory tract. Am $\mathcal{7}$ Respir Crit Care Med 1996;153:1773-80.

29 Kharitonov SA, Barnes PJ. Nasal contribution to exhaled nitric oxide during exhalation against resistance or during breatholding. Thorax 1997;52:540-4.

30 Silver M, Miller KS, Kinselia MB, Smith EA, Schabel SI. Evaluation and management of scleroderma lung disease
using bronchoalveolar lavage. Am $\mathcal{F}$ Med 1990;88:470-6.

31 Saleh D, Barnes PJ, Giad A. Increased production of the potent oxidant peroxynitrite in the lungs of patients with idiopathic pulmonary fibrosis. Am f Respir Crit Care Med 1997;155:1763-9.

32 Beckman JS, Beckman TW, Chen J, Marshall PA, Freeman BA. Apparent hydroxyl radical production by perBA. Apparent hydroxyl radical production by peroxide and superoxide. Proc Natl Acad Sci USA 1990;87: oxide and $1620-4$.

33 Barth PJ, Muller B, Wagner U, Bittinger A. Quantitative analysis of parenchymal and vascular alterations in $\mathrm{NO}_{2}$ induced lung injury in rats. Eur Respir F 1995;8:1115-21.

34 Last JA, Gelzeichter TR, Pinkerton KE, Walker RM, Witsch H. A new model of pulmonary fibrosis. Am Rev Respir Dis 1993;148:487-94

35 Dinh-Xuan AT, Higenbottam TW, Clelland CA, PepkeZaba J, Cremona G, Butt AY, et al. Impairment of endothelium-dependent pulmonary-artery relaxation in chronic obstructive lung disease. N Engl F Med 1991;324:1539-47.

36 Adnot S, Raffestin B, Eddahibi S, Braquet P, Chabrier PE. Loss of endothelium-dependent relaxant activity in the pulmonary circulation of rats exposed to chronic hypoxia. $\mathcal{F}$ Clin Invest 1991;87:155-62.

37 Barer G, Emery C, Stewart A, Bee D, Howard P. Endothelial control of the pulmonary circulation in normal and chronically hypoxic rats. I Physiol Lond 1993;463:1-16.

38 Hampl V, Archer SL, Nelson DP, Weir EK. Chronic EDRF inhibition and hypoxia: effects on pulmonary circulation and systemic blood pressure. I Appl Physiol 1993;75: 1748-57.

39 Archer S, Hampl V, McKenzie Z, Nelson D, Huang J, Shultz PJ, et al. Role of endothelial derived nitric oxide in normal and hypertensive pulmonary vasculature. Semin Respir Crit Care Med 1994;15:179-87.

40 Winkelmann BR, Kullmer TH, Kneissi DG, Trenk D, Kronenberger $\mathrm{H}$. Low-dose almitrine bismesylate in the treatment of hypoxemia due to chronic obstructive pulmonary disease. Chest 1994;105:1383-91.

41 Marasini B, Cugno M, Bassani C, Stanzani M, Bottasso B, Agostoni A. Tissue-type plasminogen activator and von Willebrand factor plasma levels as markers of endothelia involvement in patients with Raynaud's phenomenon. Int f Microcirc Clin Exp 1992;1:1.

42 Harrison NK, McAnulty RJ, Haslam PL, Black CM, Laurent GJ. Evidence for protein oedema, neutrophil influx and enhanced collagen production in lungs of patient with systemic sclerosis. Thorax 1990;45:606-10

43 Drenk F, Deicher HR. Pathophysiological effects of endothelial cytotoxic activity derived from sera of patients with progressive systemic sclerosis. F Rheumatol 1988;15: 468-74.

44 Drenk F, Mensing H, Serbin A, Deicher H. Studies on endothelial cell cytotoxic activity in sera of patients with progressive systemic sclerosis, Raynaud syndrome, rheumatoid arthritis, and systemic lupus erythematosus. Rheum atol Int 1985;5:259-63.

45 Etoh $\mathrm{T}$, Igarashi A, Iozunii $\mathrm{K}$, Ishibashi $\mathrm{Y}$, Takehara $\mathrm{K}$. The effects of scleroderma sera on endothelial cell survival in vitro. Arch Dermatol Res 1990;282:516-9.

46 Kourembanas S, McQuillan LP, Leung GK, Faller DV. Nitric oxide regulates the expression of vasoconstrictors and growth factors by vascular endothelium under both normoxia and hypoxia. f Clin Invest 1993;92:99-104.

47 Radomski MW, Palmer RN, Moncada S. Endogenous nitric oxide inhibits human platelet adhesion to vascular endothelium. Lancet 1987;ii:1057-8.

48 Radomski MW, Vallance P, Whitley G, Foxwell N, Moncada S. Platelet adhesion to human vascular endothelium is modulated by constitutive and cytokine induced nitric oxide. Cardiovasc Res 1993;27:1380-2.

49 de Graaf JC, Banga JD, Moncada S, Palmer RM, de Groot PG, Sixma JJ. Nitric oxide functions as an inhibitor of platelet adhesion under flow conditions. Circulation 1992; 85:2284-90.

50 Barrett NI, Willis AL, Vane JW. Inhibition of platelet-derived nitrogen release by nitric oxide (EDRF). Agents Action 1989;27:488-91.

51 Bath PM, Hassall DG, Gladwin AM, Paimer RM, Martin JF. Nitric oxide and prostacyclin. Divergence of inhibitory effects on monocyte chemotaxis and adhesion to endothelium in vitro. Arterioscler Thromb 1991;11:254-60.

52 Rubanyi GM, Ho EH, Cantor EH, Lumma WC, Botelho LH. Cytoprotective function of nitric oxide: inactivation of superoxide radicals produced by human leukocytes. Biochem Biophys Res Commun 1991;181:1392-7.

53 Young RH, Mark GJ. Pulmonary vascular changes in scleroderma. Am f Med 1978;64:998-1004.

54 Yousem SA. The pulmonary pathologic manifestations of the CREST syndrome. Hum Pathol 1990;21:467-74

55 Steen VD, Graham G, Conte C, Owens G, Medsgcr TA, Jr. Isolated diffusing capacity reduction in systemic sclerosis. Arthritis Rheum 1992;35:765-70. 